\title{
Investimento Estrangeiro Direto, Transbordamento e Produtividade: um estudo sobre ramos selecionados da indústria no Brasil
}

\author{
Marina Filgueiras Jorge \\ Alexis Toribio Dantas \\ Universidade do Estado do Rio de Janeiro
}

\begin{abstract}
Resumo
A partir da década de 1990, a economia brasileira passou por reformas estruturais e liberalizantes, além de intensa internacionalização produtiva. Este trabalho explora em que medida a maior participação do IED ajudou ou inibiu o processo de mudança estrutural na indústria, analisando a existência ou não de transbordamento - spillover - de produtividade, a partir da presença de empresas transnacionais em cinco cadeias produtivas selecionadas no período de 1998 a 2003. Através da análise de painel com microdados das empresas industriais, os resultados indicaram a existência de vantagens competitivas das ETNs em relação às empresas locais. Esse diferencial de desempenho, no entanto, não se mostrou uma fonte de transferência de conhecimento tecnológico que pudesse refletir em ganhos de produtividade para as empresas fornecedoras domésticas. Além disso, os efeitos sobre as cadeias produtivas mostraram-se heterogêneos. De modo que esse resultado pode ajudar no desenvolvimento de instrumentos de política industrial seletiva.
\end{abstract}

Palavras-Chave | IED; Indústria Brasileira, Spillover, Produtividade, Inovação

Códigos JEL | O33 


\section{Abstract}

During the 90s, Brazilian economy has passed through structural and liberalizing reforms, besides an intense productive internationalization. This study explores to what extent FDI helped or hindered those structural changes in industry, analyzing whether positive (or negative) productivity spillovers arose from the presence of TNCs affiliates between 1998 and 2003 in some selected industrial chains, as manufacture of electric equipments, manufacture of electronical equipments, manufacture of vehicles, manufacture of pharmaceuticals and manufacture of vegetable oils. The analysis, based on firm-level data from industrial firms and panel data techniques, produces evidences consistent with TNCs affiliates having higher productivity levels than domestic firms. However, this fact did not result in technological knowledge transfer that could reflect in productivity gains for local suppliers in upstream sectors. The results also indicate that spillovers associated with different industrial chains are heterogeneous and that this acknowledge may help the instrument design for industrial policies.

Keywords $\mid$ Brazilian Industry; Spillover; Productivity, Innovation

JEL-CODES $\mid$ O33 


\section{Apresentação}

O processo de globalização dos anos 1990 caracterizou-se por forte presença de empresas transnacionais (ETNs) oferecendo bens e serviços nos mercados domésticos e aumento da produção de conhecimento e de informação, que têm influenciado os preços de mercado e a alocação dos fatores de produção. No novo cenário, as ETNs encontram-se na fronteira do conhecimento.

No Brasil, por seu turno, as reformas da década objetivavam:

1) a desregulamentação econômica, com o fim do controle de preços, a queda das barreiras tarifárias e a eliminação de restrições ao capital estrangeiro;

2) a liberalização do setor externo; e

3) a privatização de indústrias manufatureiras e serviços públicos.

No cenário macroeconômico, também foram importantes a apreciação do câmbio e a elevação da taxa de juros com vistas à estabilização da moeda.

Quanto à estrutura produtiva brasileira, destacaram-se a modernização e a maior participação do capital estrangeiro no período 1990-2002. A modernização esteve mais ligada à racionalização, do que à expansão de capacidade e ao desenvolvimento da capacidade de inovação. A segunda mudança foi o fortalecimento do capital estrangeiro entre as firmas líderes e a sua difusão extensiva entre os setores, porém mais relevante nos segmentos mais dinâmicos.

O objetivo deste trabalho, portanto, é avaliar se houve transbordamento de produtividade, ou transferência de conhecimento tecnológico - spillover -, a partir da presença das ETNs na indústria manufatureira brasileira no período de 1998 a 2003. São analisados os efeitos intersetoriais e do desenvolvimento da capacidade de absorção.

O artigo está dividido em seis seçôes, além desta apresentação. Na primeira seção é feita uma crônica dos fatos relevantes sobre a presença do capital estrangeiro e o desempenho da indústria brasileira no período recente. Na segunda é revisada a literatura sobre investimento estrangeiro direto e transbordamento. A terceira descreve os dados e o método utilizados para avaliar o transbordamento de produtividade, a partir da presença estrangeira na indústria de transformação brasileira: o estudo empírico utilizou análise de painel para o processamento de microdados sobre as empresas industriais brasileiras no período de 1998 a 2003. A quarta seção mostra os resultados obtidos nos exercícios econométricos e, em seguida, a quinta 
seção analisa esses resultados. A última seção apresenta uma síntese da análise e as consideraçōes finais.

\section{Indústria brasileira no período recente}

Nas últimas duas décadas, os países aprofundaram o processo de integração de suas economias, com aumento dos investimentos estrangeiros diretos (IEDs) e do comércio internacional. Em consequência, aumentou a presença das ETNs nos fluxos de IED e de comércio exterior.

No Brasil, a liberalização econômica ocupou papel central no regime de incentivos e regulação, ao mesmo tempo em que a estabilização dos preços se tornou o objetivo principal da política macroeconômica (Ferraz, Kupfer \& Iooty, 2003). Esse processo de liberalização visou reduzir o papel do Estado no setor produtivo, através de um conjunto de novas regras: a abertura comercial, as privatizaçôes, a eliminação de restriçōes à "propriedade industrial", a introdução de regras de liberalização do investimento estrangeiro e a eliminação dos controles de preço e da maioria dos subsídios e incentivos fiscais (Bielschowsky, 2002).

Argumentava-se que o IED teria tido um impacto importante no substancial crescimento de produtividade durante os anos 1990, devido aos transbordamentos da eficiência produtiva e ao desenvolvimento de encadeamentos (Bonelli, 1998).

Quanto ao desempenho da balança comercial brasileira, o aumento dos fluxos de comércio exterior foi significativo, mas o padrão de especialização da indústria não apresentou grandes transformações nessa década. A participação das exportações na produção doméstica aumentou de $8 \%$ para 14,9\% entre 1990 e 2001 e a participação das importações triplicou no período: de 4,3\% para 14,8\% (Ferraz, Kupfer \& Iooty, 2003). Segundo Bielschowsky (2002:51), essa "onda importadora provocou desinvestimentos em alguns segmentos e uma fragilização desnecessária de cadeias produtivas".

Enquanto, no cenário internacional, os fluxos de comércio de produtos manufaturados cresceram a uma taxa bastante superior aos de produtos primários agrícolas e minerais e observou-se maior dinamismo nos produtos de alta intensidade tecnológica, a exportação das commodities primárias brasileiras é que apresentou maior ganho de market share. Os produtos de média e alta intensidade tecnológica e os produtos energéticos também experimentaram ganhos de market share nas exportações mundiais, mas essa participação brasileira no comércio mundial ainda se mostrou bastante pequena (Hiratuka et al., 2007:5). 
Em segundo lugar, merecem destaque os fluxos de capital estrangeiro: as intensas privatizações, fusōes e aquisições transformaram a estrutura de propriedade da indústria na segunda metade dos anos 1990.

A indústria de transformação brasileira respondeu ao processo de abertura e liberalização econômica com aumento da sua produtividade. É importante destacar, entretanto, três aspectos desse ganho. Primeiro, a eficiência produtiva foi alcançada através da racionalização de custos, mais do que com investimento em capacidade de produção ou em inovação (Kupfer, 2003). Segundo, o ganho de produtividade não resultou em mudanças estruturais significativas nem em melhor inserção internacional. Por último, o aumento de produtividade das firmas locais não induziu mudanças na sua posição relativa.

Os fluxos de IED para o Brasil na segunda metade da década de 1990 foram direcionados essencialmente como resultado do intenso processo de privatização dos serviços públicos. No período de 2001-2005, no entanto, com o esgotamento do processo de privatização, a diversificação do IED em direção à indústria manufatureira elevou a sua participação média anual de $18 \%$ para $38 \%$ do ingresso total, mas os fluxos de IED concentraram-se em alguns setores de atividades: o automobilístico se destacou por ter absorvido $24 \%$ dos investimentos estrangeiros, o químico respondeu por $20 \%$, o de alimentos e bebidas absorveu $16 \%$, ao de material eletrônico coube $11 \%$ e ao de máquinas e equipamentos, 5\% (BACEN, 2007).

De uma perspectiva mais geral, à exceção do setor de alimentos e bebidas, com baixo conteúdo tecnológico - ainda assim se mantendo acima da média da indústria (IBGE, 2005), os cinco setores que mais atraíram investimentos estrangeiros caracterizaram-se por atividades industriais com as mais elevadas taxas de inovação, candidatos potenciais à presença de efeitos de transbordamento significativos.

Inicialmente, esse processo de transnacionalização alimentou expectativas de que o aumento do IED e a maior presença da ETN resultariam em aumento da competitividade internacional da indústria e melhor desempenho da balança comercial brasileira.

Quanto ao comportamento médio das subsidiárias estrangeiras instaladas no Brasil, além de maiores, foram mais produtivas que as empresas domésticas: 4,5 vezes maiores em termos de pessoal ocupado; 11,4 vezes em termos de receita bruta; 9,6 vezes em termos de valor da transformação industrial; e, quanto à produtividade, 4,3 vezes mais produtivas que as nacionais (Araújo \& Hiratuka, 2007).

Quanto à resposta à abertura comercial e à liberalização econômica, no entanto, entre as filiais estrangeiras do complexo automobilístico, do setor de alimentos e bebidas e do setor de máquinas e equipamentos predominou a estratégia de market 
seeking com moderada orientação externa, enquanto as do setor de material eletrônico e de comunicação e do setor químico adotaram estratégias market seeking com baixa orientação externa (Sarti \& Laplane, 2002): as filiais brasileiras das ETNs estiveram mais integradas ao mercado internacional, sem que isso tenha significado um resultado comercial mais favorável (De Negri, 2003).

A presença do capital estrangeiro na indústria brasileira, além disso, implicou acelerada desnacionalização, com concentração das filiais estrangeiras entre as empresas grandes e nos setores da indústria baseada em ciência (controle de $82 \%$ do total), da indústria de produção diferenciada $(73 \%)$ e da indústria de produção contínua em escala (68\%). Na indústria intensiva em recursos naturais, a participação estrangeira experimentou forte crescimento: de 15\% para 24\% entre 1985 e 2002 (Lessa, 2007).

Segundo os dados da PINTEC 2000, por outro lado, as empresas estrangeiras concentraram-se nas categorias de firmas que inovam e diferenciam produtos e de firmas especializadas em produtos padronizados, ao passo que as empresas nacionais se concentraram na categoria das que não diferenciam produtos e têm produtividade menor, ou que se especializam em produtos padronizados. As evidências, além disso, indicaram menor participação dos gastos de P\&D das ETNs (Araújo, 2005).

Quanto às interações das ETNs, os elos com o exterior mostraram-se mais fortes do que com o SNI brasileiro. Nesse sentido, as filiais brasileiras das ETNs poderiam ter desempenhado um papel mais relevante no desenvolvimento tecnológico e no aumento da competitividade industrial (Hiratuka, 2003).

Apesar de que, comparadas com as firmas domésticas, as ETNs utilizaram mais formas de cooperação para inovar: utilizaram outra empresa do grupo no exterior como principal fonte de cooperação, depois cooperaram com seus clientes e fornecedores no Brasil e utilizaram, em maior proporção, as universidades, os centros de pesquisa $(16,7 \%$ contra $10 \%)$ e os centros de capacitação profissional e assistência técnica $(10,8 \%$ contra $8 \%)$.

Tendo em vista esse cenário, uma das principais questôes sobre o impacto da entrada de ETNs refere-se à capacidade efetiva dessas empresas em contribuir para o aumento de competitividade das firmas nacionais.

\section{Investimento estrangeiro direto e transbordamento}

Em que pesem as vantagens competitivas apontadas das ETNs em relação às empresas domésticas, os impactos da atuação do IED em economias hospedeiras não são automáticos. 
Normalmente, as firmas decidem se engajar em atividades de valor adicionado no exterior, quando possuem algum tipo de ativo intangível, como a propriedade de conhecimentos tecnológicos, gerenciais e organizacionais, de modo a ganhar maior competitividade e melhorar a sua posição competitiva (Dunning, 1994).

Nesse contexto, a transferência de conhecimento pode-se dar de forma direta, através da aquisição de uma firma local pelo capital estrangeiro e da transferência de tecnologia e de métodos de gerenciamento às novas filiais, embora esse efeito não seja considerado transbordamento.

Em segundo lugar, a transferência de tecnologia pode-se dar de forma indireta, através de relações competitivas intrassetoriais, o que caracteriza o efeito transbordamento horizontal. No entanto, argumenta-se que o transbordamento horizontal seja mais improvável de ocorrer, pois as empresas têm incentivos de impedir o vazamento da informação que possa melhorar o desempenho de seus concorrentes.

Por último, existe a possibilidade de que haja transferência de tecnologia através das relaçôes intersetoriais, ou seja, através dos mercados de insumo e produto, que, por sua vez, caracteriza o efeito transbordamento vertical.

O primeiro tipo de transbordamento vertical ocorre quando as empresas domésticas se tornam mais produtivas, ao criarem elos com ETNs fornecedoras de insumos, relacionados ao acesso a novos insumos melhores e com menores custos em relação aos insumos doméstico, ou comparativamente aos produtos importados.

Outro tipo de efeito de transbordamento vertical pode ocorrer a partir de contatos entre ETNs e seus fornecedores locais, através de

1) transferência direta de conhecimento dos clientes estrangeiros para os fornecedores locais;

2) maior exigência por parte da ETN quanto à qualidade do produto e ao prazo de entrega;

3) entrada da ETN, podendo aumentar a demanda por produtos intermediários, o que permite que as empresas locais se beneficiem de economias de escala (Javorcik, 2004).

Esses encadeamentos produtivos para trás, em especial, podem constituir um canal direto para a difusão de conhecimento, que, por sua vez, pode ajudar as empresas locais a realizarem um upgrade tecnológico e de capacidades, com efeitos de transbordamento para toda a economia. Essa difusão de conhecimento é de particular importância para as empresas que ainda buscam atingir a competitividade internacional. 
As evidências de que a presença dos investidores externos produz externalidades positivas não são, no entanto, claras. Os estudos dos impactos do IED na economia hospedeira apresentaram resultados divergentes.

Em estudo sobre a influência do IED sobre a produtividade do trabalho das firmas domésticas da Hungria de Schoors e Van der Tol (2002), por exemplo, os resultados mostraram que as empresas estrangeiras tinham maior produtividade do que as empresas locais; o transbordamento intrassetorial para as empresas locais foi positivo, porém não foi significativo; as firmas locais mais desenvolvidas eram mais capazes de se beneficiarem da interação da presença do IED com o nível de absorção definido como o capital humano por empregado; e o grau de abertura do setor foi importante para o tamanho do efeito transbordamento setorial do IED. Além disso, o transbordamento intersetorial revelou-se maior do que o transbordamento intrassetorial e o efeito do IED-cliente para as empresas locais fornecedoras de insumos foi positivo, enquanto o efeito do IED-fornecedor para as empresas locais de produtos finais foi negativo.

O estudo de Javorcik (2004), por sua vez, mostrou a existência de transbordamento positivo a partir do IED-cliente para seus fornecedores locais. As evidências, no entanto, não foram robustas quanto aos transbordamentos horizontais ou através de canais das empresas locais compradoras com produtores estrangeiros de insumos. Revelou, ainda, que a participação do capital doméstico nos projetos de IED resultou em maior encadeamento com a economia local e em maiores transbordamentos de produtividade para produtores locais de insumos.

Já no estudo sobre a indústria manufatureira na Colômbia de Kugler (2006), as externalidades intraindústria foram limitadas, enquanto as interindústria foram importantes, reforçando a hipótese de que o derrame de conhecimento da ETN só ocorre com informações genéricas, de modo a evitar a melhora de desempenho dos competidores.

Em Chudnovsky et al. (2004), a análise com o objetivo de medir a magnitude do transbordamento de IED na Argentina permitiu destacar que

1) as ETNs são mais produtivas do que as empresas domésticas;

2) não há presença significativa de transbordamento horizontal nem vertical (para trás);

3) as empresas domésticas com alta capacidade de absorção se beneficiam mais do efeito positivo do IED, indicando que o grau de desenvolvimento das empresas locais é uma questão determinante para o melhor aproveitamento das externalidades geradas pelo IED. 
No estudo de caso de Ciarli e Giuliani (2005), por seu turno, a análise do impacto da empresa INTEL na Costa Rica indicou que, apesar da atração de IED ter sido orientada para os setores industriais de alta tecnologia, a escassez de encadeamentos e a sua debilidade, principalmente dos encadeamentos para trás, geraram uma limitada capacidade de reduzir a heterogeneidade estrutural.

Quanto à indústria brasileira, em particular, em Gonçalves (2003), o autor obteve que o transbordamento horizontal depende do nível de desenvolvimento das empresas domésticas - as empresas domésticas mais produtivas perdendo market share. Com relação à estratégia das filiais estrangeiras, os resultados apontaram que as empresas domésticas localizadas em setores em que as filiais estrangeiras eram resource seeking eram cerca de $18 \%$ menos produtivas do que as que atuavam em setores em que essas filiais eram market seeking. Evidenciou, ainda, grande potencial de geração de transbordamentos por meio de encadeamentos para trás.

E, finalmente, Araújo (2005) procurou relacionar tais efeitos aos esforços de inovação. Seus resultados mostraram que houve uma predominância de efeitos positivos de transbordamento devido tanto a um aumento da presença estrangeira, como a um aumento dos seus gastos com $P \& D$ em relação à receita líquida de vendas. Destacou que as ETNs inovaram com mais frequência, em comparação com as firmas domésticas e que estas apresentavam atitude mais adaptativa do que propriamente inovadora, refletindo as necessidades da relação fornecedor-comprador entre as firmas domésticas e as ETNs.

Diante das evidências expostas nessa literatura, então, a dinâmica do efeito transbordamento vertical do IED na indústria brasileira que será examinada é resultado de combinação da estratégia de escolha dos mercados e das atividades de inovação das filiais das ETNs, com a capacidade de absorção das empresas locais.

O desenvolvimento econômico, a propósito, está relacionado à possibilidade de transformação da estrutura produtiva, em que a inovação, o trabalho qualificado, o investimento e a informação desempenham papel central (Cimoli et al., 2005; Ciarli \& Giuliani, 2005). Ao mesmo tempo em que a capacidade de inserção das exportaçóes de um país nos fluxos de comércio mais dinâmicos representa uma oportunidade para reduzir as brechas tecnológicas entre países desenvolvidos e em desenvolvimento. As diferentes dinâmicas, no comércio internacional e no crescimento, dão origem, de fato, a brechas tecnológicas entre países desenvolvidos e em desenvolvimento.

No período recente, a propósito, os produtos manufaturados têm aumentado a sua participação relativa nos fluxos de comércio, em comparação com os produtos 
primários agrícolas e minerais. Além disso, entre os produtos manufaturados, aqueles com maior intensidade tecnológica têm experimentado maior ritmo de crescimento (Hiratuka et al., 2007).

Apesar da melhora de desempenho das exportações brasileiras, no entanto, a estrutura da sua pauta de exportaçóes ficou praticamente inalterada. O aumento observado do market share ocorreu, principalmente, em função do aumento da participação das commodities primárias. Entre os produtos mais dinâmicos, a inserção das exportações brasileiras ainda tem sido muito pequena. Sendo assim, a capacidade interna de incorporação de progresso técnico estaria condicionada à capacidade de absorver os conhecimentos tecnológicos produzidos pelas firmas dos países desenvolvidos, de absorver o fruto das novas trajetórias tecnológicas para modificar a composição setorial da sua indústria e difundir as mudanças tecnológicas para o resto da economia. E, no nível da firma, a capacidade de aprendizado é um fator importante para que a firma incorpore as novas tecnologias vindas de outras firmas ou de outros países.

\section{Investimento estrangeiro e posicionamento estratégico}

No contexto desse debate, acreditou-se em certos círculos que as firmas mais competitivas teriam assegurado o efeito positivo do aumento da presença estrangeira no mercado nacional, bem como do transbordamento de conhecimento sobre os canais de distribuição internacional de mercadorias. $\mathrm{O}$ choque de competitividade levaria ao aumento do investimento e da produtividade (Franco, 1998). Através do acesso à tecnologia e aos mercados, a transferência de ativos intangíveis teria efeito positivo para o crescimento das exportaçōes (Fritsch \& Franco, 1989).

Segundo Sarti e Laplane (2002), ao contrário, as transformações recentes da economia brasileira se manifestaram na estrutura produtiva como um processo de "internacionalização introvertida" e aquelas expectativas quanto aos transbordamentos de conhecimentos específicos sobre comércio internacional não se realizaram.

De maneira equivalente para De Negri (2003), as empresas estrangeiras têm vantagens competitivas e maior potencial exportador do que as nacionais, mas a pequena diferença entre coeficientes de exportação dos dois grupos de empresas, aliada a uma substancial diferença nos coeficientes de importação, parece indicar que essas vantagens não resultaram em desempenho comercial mais favorável das empresas estrangeiras.

Esse diferencial de desempenho entre as empresas poderia, de fato, representar uma fonte potencial para a ocorrência de transbordamentos verticais de produtividade, 
visto que as empresas estrangeiras poderiam ter interesse em aumentar a eficiência na sua cadeia produtiva local. $\mathrm{O}$ que ocorre, no entanto, é que, em muitos casos, as redes de fornecimento global são mantidas, os fornecedores locais são preteridos e o transbordamento negativo ocorre, pois causa a redução de escala de produção ou o downgrading da linha de produto (Araújo \& Hiratuka, 2007).

Segundo Cimoli et al. (2005:9), além disso, nem todos os setores são capazes de difundir conhecimento. Na América Latina, segundo eles, o peso dos setores difusores de conhecimento tem-se mantido muito inferior ao das economias mais exitosas e, no caso do Brasil, em particular, esses setores representaram $31 \%$ da estrutura produtiva em 2000.

Ferraz, Kupfer e Iooty (2003) chamaram a atenção, ainda, para o paradoxo de que, se em experiências exitosas do cenário internacional, o capital local e a capacidade de inovação foram características marcantes para o desenvolvimento econômico sustentado, no modelo de desenvolvimento adotado no Brasil, a participação estrangeira no capital das firmas aumentou junto com o baixo investimento em $\mathrm{P} \& \mathrm{D}$, considerado por elas de alto risco.

Diante das experiências exitosas, como a da Alemanha no século XIX e a do Japão no século XX, por exemplo, que registraram estratégias tecnológicas de complementaridade entre a importação de tecnologias e o desenvolvimento doméstico de capacidades tecnológicas (Viotti, 2002), o processo de mudança técnica nas economias de industrialização tardia deve ser avaliado por sua capacidade de aprendizado, ou seja, pela absorção de técnicas já existentes.

Para outros autores, finalmente, a evolução da produtividade no Brasil explica-se melhor pelo tamanho das empresas, do que pelo setor de atividade, seus resultados indicando forte heterogeneidade na indústria brasileira e capacidades de resposta diferentes das empresas (Kupfer \& Rocha, 2005).

\section{Importância da capacidade de absorção}

Sob a ótica dessas abordagens, portanto, o estoque de conhecimento e de tecnologia pode aumentar tanto pelo investimento direto em $\mathrm{P} \& \mathrm{D}$, quanto pela difusão da tecnologia existente. $\mathrm{O}$ aumento de produtividade das firmas está estreitamente relacionado às suas atividades de $\mathrm{P} \& \mathrm{D}$ e/ou ao transbordamento de tecnologia desde empresas mais produtivas. Segundo Dunning (1994), é provável que a base de $\mathrm{P} \& \mathrm{D}$ do país saia fortalecida, se as atividades das empresas forem complementares. A globalização das atividades de $\mathrm{P} \& \mathrm{D}$, no entanto, vem acontecendo em ritmo mais lento do que a de outras funções das ETNs (Hiratuka, 2003). 
Em estudo do aumento de produtividade das firmas tchecas, por exemplo, os efeitos da presença estrangeira não foram significativos, mas tornam-se positivos e significativos quando a análise considera as interaçōes das variáveis referentes a IED e a P\&D, concluindo-se que a atividade de P\&D é fundamental, pois desenvolve a capacidade de absorção de tecnologias existentes (Kinoshita, 2001).

Quanto à indústria argentina, Chudnovsky et al. (2004) estudaram a importância do grau de desenvolvimento das empresas locais e, da mesma forma, destacaram que as empresas com alta capacidade de absorção - medida por um índice composto por características da mão de obra e do esforço inovador - são as mais propensas a se beneficiarem do efeito positivo do transbordamento a partir da presença de IED.

Em estudo sobre a indústria brasileira, no entanto, a capacidade de aprendizado foi definida como a produtividade relativa das empresas domésticas, em comparação com a das ETNs, obtendo-se uma relação negativa entre os transbordamentos de produtividade e o nível de desenvolvimento das empresas domésticas (Gonçalves, 2003).

Quanto à definiçãoo de capacidade de absorção, em específico, De Negri (2006) examinou a relação entre a capacidade de absorção das firmas brasileiras, o seu esforço tecnológico e o perfil de mão de obra empregada. Constatou, como fatores importantes da capacidade de absorção das firmas,

1) o nível de qualificação dos trabalhadores;

2) a existência de uma unidade formal de $P \& D$ (como sendo a realização de atividades contínuas de $\mathrm{P} \& \mathrm{D})$;

3) o gasto relativo de $P \& D$ na receita líquida de vendas;

4) a combinação de gasto em treinamento e tempo de emprego médio.

Em suma, o IED é um instrumento em potencial para o desenvolvimento econômico, mas requer a presença de capital humano capacitado, de infraestrutura bem desenvolvida e de clima econômico estável. Os efeitos indiretos e os transbordamentos de IED não são consequência automática da presença de ETN na economia local, dependem dos esforços de P\&D e do aprendizado das firmas locais, ou seja, dependem da capacidade local de absorção de conhecimento.

\section{Metodologia e dados básicos}

A maioria dos estudos realizados de análise estatística sobre transbordamentos esteve focada nos efeitos intrassetoriais. $\mathrm{O}$ nosso interesse neste trabalho esteve focado 
nos encadeamentos produtivos verticais para trás e nas possíveis transferências de conhecimento e tecnologia que se processam por meio desses elos, de modo a afetar a eficiência da firma doméstica.

$\mathrm{Na}$ indústria de transformação brasileira, como vimos no capítulo anterior, os fluxos de IED estiveram mais concentrados em cinco setores de atividades do nível CNAE-2 da Classificação Nacional de Atividades Econômicas - CNAE, que serão objeto da análise: alimentos e bebidas, produtos químicos, máquinas e equipamentos, materiais eletrônicos e veículos automotores.

\section{Dados básicos, amostra e estatísticas descritivas}

O banco de dados utilizado neste estudo foi organizado pelo Instituto de Pesquisa Econômica Aplicada (IPEA), em que o cruzamento dos microdados de diversas pesquisas institucionais importantes resultou em um importante mapa da indústria brasileira. Entre os microdados disponíveis, estão os da Pesquisa Industrial Anual (PIA) e da Pesquisa Industrial de Inovação Tecnológica (PINTEC) do Instituto Brasileiro de Geografia e Estatística (IBGE); da Secretaria de Comércio Exterior (SECEX) do Ministério de Desenvolvimento, Indústria e Comércio Exterior (MDIC); do Censo de Capitais Estrangeiros (CCE) do Banco Central; e da Relação Anual de Informações Sociais (RAIS) do Ministério do Trabalho e Emprego (MTE). ${ }^{1}$

Para a construção da amostra, a principal base de dados utilizada foi a PIA, que reúne, entre outras informações econômico-financeiras sobre o setor industrial brasileiro, a receita líquida de venda da firma, o seu valor da transformação industrial e o número médio de pessoal nela ocupado no ano. A pesquisa é estruturada segundo um estrato certo com todas as empresas com mais de 30 pessoas ocupadas e um estrato aleatório entre as firmas de 10 a 30 pessoas ocupadas.

As informações da PINTEC, por sua vez, concentram-se nas inovações tecnológicas das empresas e nas atividades que empreendem para inovar. As publicaçōes da PINTEC 2000 e 2003, alinhadas aos padrōes metodológicos internacionais sugeridos pelo Manual de Oslo de quantificação de atividades de C\&T (IBGE, 2005), contêm informações sobre os esforços tecnológicos das firmas. Dessa forma, são publicações essenciais para podermos construir proxies da capacidade de absorção das firmas domésticas e do esforço tecnológico das firmas estrangeiras. A amostra da PINTEC,

1 Por comprometimento com o sigilo das informações das pesquisas, os dados foram criptografados, para que as empresas não pudessem ser reconhecidas. Pelo mesmo motivo, o trabalho foi todo realizado em uma sala de consulta do IBGE e avaliado pela equipe do IBGE no intuito de manter o sigilo. 
que é estruturada de maneira diferente à da PIA, contém estrato aleatório entre as firmas de 10 a 500 pessoas ocupadas e estrato censitário apenas entre as firmas industriais brasileiras com mais de 500 pessoas ocupadas.

Já a base da SECEX corresponde a um cadastro com o registro das operaçóes (importação e exportação de mercadorias) realizadas pelas empresas do Brasil ao longo do ano. Foram adicionadas a essa base principal as informaçōes da SECEX sobre os valores das exportaçôes e das importações agregados por empresa e ano.

Além disso, a base do CCE/BACEN contém o registro de toda empresa que possui participação de capital estrangeiro no seu ativo total e possibilita separar as firmas domésticas e as estrangeiras.

E, finalmente, a base da RAIS/MTE capta, em essência, as características específicas do trabalhador, como o grau de escolaridade e o tempo de emprego, entre outras.

Este estudo restringiu a análise, primeiramente, apenas aos dados referentes às atividades classificadas na seção D (Indústria de Transformação) da CNAE e aos anos de 1998 a 2003. A escolha desse período justifica-se pelo fato de que a magnitude do efeito de transbordamento de conhecimento a partir da presença estrangeira pode estar associada tanto ao nível de desenvolvimento tecnológico das firmas domésticas, quanto ao esforço tecnológico das subsidiárias estrangeiras, sendo a PINTEC (19982000 e 2001-2003) a principal fonte de tais informaçôes.

Em seguida, foi feita uma demarcação dos segmentos de bens de consumo final de nível CNAE-3 em cada um dos cinco setores de atividade de nível CNAE-2 selecionados, para poder estimar o efeito sobre as suas cadeias. Para utilizar os coeficientes intersetoriais da Matriz Insumo Produto de 1996 e selecionar as principais atividades fornecedoras para cada segmento assim demarcado, foi necessária, no entanto, uma nova agregação das atividades desses segmentos, através da sua correspondência com a classificação do Sistema de Contas Nacionais (SCN). Esse corte foi feito para permitir a análise comparativa dos impactos entre as subsidiárias estrangeiras que se localizam na ponta final de diferentes cadeias produtivas (ver Anexo).

Sendo assim, fixamo-nos nas seguintes atividades econômicas: fabricação de aparelhos e equipamentos de material elétrico (setor 10); fabricação de aparelhos e equipamentos de material eletrônico (setor 11); fabricação de automóveis, caminhōes e ônibus (setor 12); fabricação de produtos farmacêuticos e de perfumaria (setor 20); e fabricação e refino de óleos vegetais e de gorduras para alimentação (setor 30).

Para a definição da cadeia produtiva de cada segmento selecionado, usamos, como critério para os principais fornecedores, os setores industriais que apresentavam 
TABELA 1

Produtividade anual média das empresas manufatureiras, período 1998-2003 ( $\mathrm{R} \$$ /trabalhador, a preços correntes)

\begin{tabular}{lcc}
\hline Setor & Empresas domésticas & Empresas estrangeiras \\
Produtos elétricos & $37.815,63$ & $78.404,06$ \\
Produtos eletrônicos & $55.477,73$ & $173.758,99$ \\
Automóveis, caminhões e ônibus & $41.942,82$ & $115.651,79$ \\
Produtos farmacêuticos & $61.364,45$ & $155.942,94$ \\
Óleos vegetais & $88.590,92$ & $218.557,43$ \\
\hline
\end{tabular}

Fonte: PIA/IBGE e CEB/BACEN.

um coeficiente intersetorial maior do que $1 \%$, à exceção da cadeia produtiva de óleos vegetais, em que usamos os coeficientes acima de $0,1 \%$. O número de setores classificados como fornecedores em cada cadeia produtiva difere e é apresentado no Anexo.

O cruzamento dos dados por empresa da PIA com os da PINTEC apresentou, no entanto, inúmeras dificuldades, pois as pesquisas não possuem o mesmo corte amostral. Como vimos, em ambas as pesquisas, o estrato entre as firmas com menos de 30 empregados é aleatório. De maneira que, para a realização deste trabalho, excluímos da amostra as empresas dessa faixa e construímos uma segunda amostra por grupos de empresas segundo faixas de pessoal ocupado. ${ }^{2}$ Assumimos que as firmas agrupadas em uma mesma faixa possuem o mesmo padrão tecnológico.

Numa primeira apresentação dos dados, segundo a Tabela 1, podemos verificar que, em média, a produtividade das empresas estrangeiras foi maior do que a produtividade das empresas domésticas nos mesmos cinco setores. De acordo com esse diferencial de produtividade, poder-se-ia interpretar a presença de ETN como uma fonte potencial para a transferência tecnológica para a indústria brasileira.

2 Segundo a classificação de porte de empresa industrial do IBGE, discriminamos em três faixas: de 30 a 99 empregados (pequena empresa), de 100 a 499 empregados (média empresa) e de 500 para mais empregados (grande empresa). 
$\mathrm{Na}$ literatura específica sobre os efeitos da presença de empresas estrangeiras na produtividade das empresas domésticas, o instrumental econométrico que tem sido mais utilizado é o de modelos de regressão com dados em painel. As técnicas de dados em painel podem resolver, ou ajudar a resolver, alguns tipos de viés de omissão de variáveis e, assim, obter estimadores consistentes. Além disso, permitem controlar a heterogeneidade individual não observada, que é o principal problema na pesquisa não experimental.

Nesse sentido, foram estimados dois grupos de dois modelos. O primeiro grupo de dois modelos objetivou estimar se a presença do capital estrangeiro teve efeito sobre a produtividade das empresas, em uma amostra com todas as empresas, ou sobre a produtividade de suas fornecedoras de insumos, em amostras com empresas domésticas apenas. $\mathrm{O}$ segundo grupo de dois modelos procurou verificar se a capacidade de absorção das empresas domésticas teve alguma influência nos efeitos de transbordamento.

Em todos os quatro modelos estimados, a variável dependente é o logaritmo natural do nível de produtividade da firma, definida pelo valor de transformação industrial dividido pelo pessoal ocupado da firma, do período de 1999 a 2003. Para evitar problemas de endogeneidade nos modelos estimados, utilizamos as variáveis explicativas defasadas no ano $t-1$, ou seja, do período de 1998 a 2002.

Seguimos a metodologia da função Cobb Douglas, para representar a produtividade da firma; procedemos à inclusão da proporção de pessoal ocupado com nível superior, da presença de investimento estrangeiro e dos coeficientes de exportação e importação como variáveis explicativas adicionais que poderiam afetar a produtividade da firma (Chudnovsky et al., 2004). O efeito de transbordamento a partir da presença estrangeira é examinado através do seu coeficiente específico.

Inicialmente, as estimativas do Modelo 1A foram feitas em uma amostra com firmas domésticas e estrangeiras para testar a Hipótese 1, de que a empresa transnacional tenderia a ser mais produtiva do que a empresa doméstica. A maior participação do capital estrangeiro, portanto, teria efeito direto positivo sobre a produtividade da firma.

Modelo 1A: existência de transbordamento direto

$$
\begin{aligned}
& \ln \left(P R O D_{i j, t}\right)=\beta_{0}+\beta_{1} \ln \left(T A_{-} P O_{i j, t-1}\right)+\beta_{2} \ln \left(E P_{-} P O_{i j, t-1}\right)+\beta_{3} I E D_{j i t}+ \\
& \beta_{4} \ln \left(X_{i j, t-1}\right)+\beta_{5} \ln \left(M_{i j, t-1}\right)+\beta_{6} S E T O R_{j}+\beta_{7} R_{r}+\beta_{8} A N O_{t}+\varepsilon_{i j t}
\end{aligned}
$$


Onde:

- $\mathrm{PROD}_{\mathrm{ij}, \mathrm{t}}$ - representa a produtividade da firma $i$ do setor $j$ no ano $t$, medida como o valor da transformação industrial dividido pelo número médio de pessoal ocupado no ano (VTI/PO);

- TA_PO $\mathrm{i}_{\mathrm{ij}, \mathrm{t}-1}$ - representa o tamanho da firma $i$ do setor $j$ no ano $t$-1, medido pelo número médio de pessoal ocupado no ano;

- EP_PO $\mathrm{Pi}_{\mathrm{i}, \mathrm{t}-1}$ - representa a eficiência produtiva da mão de obra empregada, medida como a participação de funcionários com nível superior no total de pessoal ocupado da firma $i$ do setor $j$ no ano $t-1$;

- $\mathrm{IED}_{\mathrm{ijt}}$ - variável dummy que identifica se a firma é estrangeira no ano $t$;

- $\mathrm{X}_{\mathrm{it}-1}$ - representa o coeficiente de exportação da firma $i$ do setor $j$, medido pelo valor das exportações dividido pela receita líquida de vendas;

- $\mathrm{M}_{\mathrm{it}-1}$ - representa o coeficiente de importação da firma $i$ do setor $j$, medido pelo valor das importações dividido pela receita líquida de vendas;

- $\mathrm{SETOR}_{\mathrm{j}}$ - (n-1) dummies que identificam o setor, classificado segundo o SCN, de atuação da empresa doméstica $i$;

- $\mathrm{R}_{\mathrm{r}}-(\mathrm{n}-1)$ dummies que identificam a região da firma;

- $\mathrm{ANO}_{\mathrm{t}}-(\mathrm{n}-1)$ dummies que identificam o ano de referência.

A ETN é definida, pelo BACEN, como a empresa com $i$ participação estrangeira acima de 50\% no capital acionário votante. A metodologia desenvolvida por De Negri (2003) a partir do cruzamento de informaçōes do CCE de 1995 e 2000 permitiu acompanhar as mudanças de controle de capital nesse período. Para o período 2000-2003, a condição de empresa estrangeira em 2000 foi mantida.

As dummies de controle do setor de atividade, da região onde a firma se localiza e de ano foram incluídas para lidar com problemas de omissão de variáveis não observadas que poderiam afetar a correlação entre produtividade da firma e presença estrangeira. Por exemplo, essas variáveis estariam relacionadas à melhor infraestrutura ou aos avanços tecnológicos de uma localidade (ou de um setor), que poderiam afetar sua atratividade (Javorcik, 2004).

Em seguida, a intenção foi estimar se a presença do capital estrangeiro nos cinco setores selecionados teve efeito sobre a produtividade das empresas domésticas fornecedoras, como ilustrado no Quadro 1 abaixo. A Hipótese 2 é de que as relações mais propícias à geração de externalidades tendem a ser entre a ETN-cliente e os seus fornecedores locais (efeito vertical para trás), se comparadas às relações entre a 
ETN-fornecedora e os clientes locais (efeito vertical para frente). Do Modelo 1B em diante, a amostra incluiu apenas firmas domésticas e a variável dependente passou a apresentar o sobrescrito $d$.

Modelo 1B: existência de transbordamento indireto

$$
\begin{aligned}
& \ln \left(P R O D_{i j, t}^{d}\right)=\beta_{0}+\beta_{1} \ln \left(T A_{-} P O_{i j, t-1}\right)+\beta_{2} \ln \left(E P_{-} P O_{i j, t-1}\right)+\beta_{3} \ln \left(X_{i j, t-1}\right)+\beta_{4} \ln \left(M_{i j, t-1}\right)+ \\
& \beta_{5} \ln \left(T R A S_{j, t-1}\right)+\beta_{6} S E T O R_{j}+\beta_{7} R_{r}+\beta_{8} A N O_{t}+\varepsilon_{i j t}
\end{aligned}
$$

Onde, além das variáveis já explicadas:

- TRAS $_{\mathrm{j}, \mathrm{t}-1}$ - representa o efeito de transbordamento intersetorial a partir das firmas estrangeiras para as firmas fornecedoras de insumos do setor $j$ e permite isolar o efeito $\beta_{5}$ de transbordamento intersetorial a partir das firmas estrangeiras para as firmas fornecedoras de insumos do setor $j$, quando o IED se localiza no setor $k$, sendo $k$ (cliente) $\neq j$ e compra do setor $j$ (fornecedor). O efeito de encadeamento para trás total sobre o setor $j$ será medido como a proporção $\alpha_{j k}$ do insumo $j$ no produto $k$ multiplicada pela participação estrangeira no setor $k$, ou seja:

$$
T R A S_{j, t-1}=\sum_{k \leftrightarrow k \neq j} \alpha_{j k} \operatorname{INTRA}_{j, t-1}
$$

- INTRA $_{\mathrm{jt}}$ - permite isolar o efeito $\beta$ de transbordamento intrassetorial; a participação estrangeira no setor $j$ é medida como a participação no valor da transformação industrial das firmas transnacionais (aquela com CE > 50\%) do setor $j$ sobre o valor da transformação industrial de todas as firmas do setor $j$, ou seja:

$$
\operatorname{INTR}_{j, t-1}=\left[\sum_{i \forall i \in j} I E D_{i, t-1} * Y_{i, t-1}\right] / \sum_{i \forall i \in j} Y_{i, t-1}
$$

Para analisar se a presença estrangeira tem efeitos indiretos sobre a produtividade da firma doméstica localizada em setores fornecedores, os modelos foram rodados para cinco amostras, uma para cada um dos cinco setores de atividades $(k)$ 
QUADRO 1

Relações intersetoriais da empresa transnacional

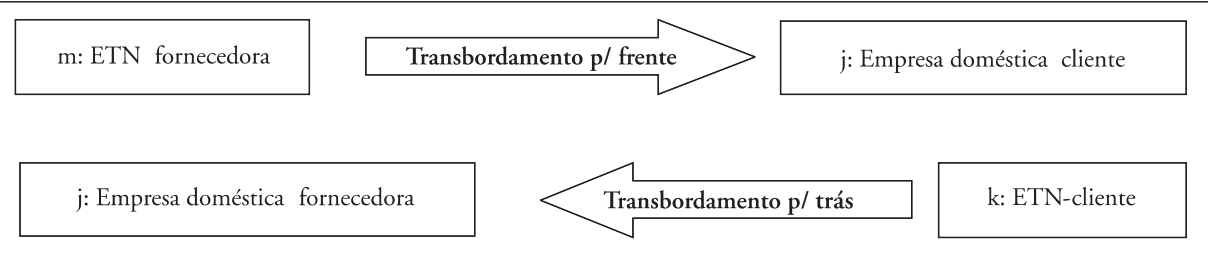

selecionados. Em cada amostra, a variável dependente é a produtividade do trabalho das firmas ( $i$ ) localizadas nos setores fornecedores $(j)$. Sendo assim, o número de dummies de controle do setor de atividade das firmas fornecedoras vai depender da sua cadeia produtiva específica (ver Anexo).

A capacidade de absorção ou aprendizado foi abordada de diferentes maneiras: pela medida da brecha de produtividade, pelo grau de intensidade da qualificação da mão de obra e pela natureza das atividades tecnológicas.

No segundo grupo de modelos, então, assumindo a Hipótese 3, de que o nível de desenvolvimento das firmas domésticas criaria maiores oportunidades para o aproveitamento das externalidades geradas, influenciando na existência e na magnitude do efeito de transbordamento a partir das firmas estrangeiras clientes, utilizamos algumas proxies para a capacidade de absorção das firmas brasileiras. A capacidade de absorção das empresas brasileiras foi aqui abordada a partir de duas medidas alternativas, a saber:

1) de acordo com a PINTEC, podemos identificar quanto a empresa gasta com atividades internas de $\mathrm{P} \& \mathrm{D}$. A realização contínua de atividades de $\mathrm{P} \& \mathrm{D}$, geralmente, depende de um departamento próprio para essas atividades e, portanto, a empresa deve ter a inovação tecnológica na sua rotina e na sua estratégia competitiva, para aumentar a sua capacidade de aprendizado;

2) de acordo com a RAIS, podemos verificar o perfil da mão de obra empregada, como sendo a escolaridade média dos trabalhadores, medida como a participação de funcionários com nível superior no quadro de pessoal da firma.

As variaçôes do segundo modelo também foram rodadas para cinco amostras, $\mathrm{e}$ incluíram as variáveis mencionadas acima, que descrevem a capacidade de absorção 
da firma doméstica, interagindo com o efeito de transbordamento a partir da presença de firmas estrangeiras compradoras:

Modelo 2A: efeito parcial da capacidade de absorção, medida pelo investimento em P\&D

$\ln \left(P R O D^{d}{ }_{i j, t}\right)=\beta_{0}+\beta_{1} \ln \left(T A_{-} P O_{i j, t-1}\right)+\beta_{2} \ln \left(E P_{-} P O_{i j, t-1}\right)+\beta_{3} \ln \left(X_{i j, t-1}\right)+\beta_{4} \ln \left(M_{i j, t-1}\right)+$ $\beta_{5} \ln \left(T_{R A S} S_{j, t-1}\right)+\beta_{6} \ln \left(C_{-} P \& D_{j, t-1}\right)+\beta_{7}$ SETOR $_{j}+\beta_{8} R_{r}+\beta_{9} A N O_{t}+\varepsilon_{i j t}$

Onde:

- CA_P\&D $\mathrm{D}_{\mathrm{j}, \mathrm{t}-1}$ - representa a capacidade de absorção medida como a interação das variáveis TRAS e uma proxy da participação do investimento em P\&D da firma $i$ no setor $j$ no ano $t-1$.

$$
C A_{-} P \& D_{i j, t-1}=T R A S_{j, t-1} * \frac{P \& D_{i j, t-1}}{R L V_{i j, t-1}}
$$

Modelo 2B: efeito parcial da capacidade de absorção, medida pela participação da mão de obra qualificada

$\ln \left(P R O D_{i j, t}^{d}\right)=\beta_{0}+\beta_{1} \ln \left(T A_{-} P O_{i j, t-1}\right)+\beta_{2} \ln \left(E P_{-} P O_{i j, t-1}\right)+\beta_{3} \ln \left(X_{i j, t-1}\right)+\beta_{4} \ln \left(M_{i j, t-1}\right)+$ $\beta_{5} \ln \left(T R A S_{j, t-1}\right)+\beta_{6} \ln \left(C A_{-} P O_{j, t-1}\right)+\beta_{7} S$ TOR $_{j}+\beta_{8} R_{r}+\beta_{9} A N O_{t}+\varepsilon_{i j t}$

Onde:

- CA_PO ${ }_{\mathrm{j}, \mathrm{t}-1}$ - representa a capacidade de absorção medida como a interação das variáveis TRAS e a participação de funcionários com nível superior no total de pessoal ocupado da firma $i$ do setor $j$ no ano $t-1$.

$C A_{-} P O_{i j, t-1}=T R A S_{j, t-1}^{*} E P_{-} P O_{i j, t-1}$

A proxy da participação do investimento em $\mathrm{P} \& \mathrm{D}$ da firma foi construída através dos dados da PINTEC. A amostra da PINTEC é resultado, em sua maior parte, de uma amostragem aleatória. Assim, a variável representa a razão média do investimento em P\&D em relação à receita líquida de vendas de todas as empresas domésticas de mesmo porte e localizadas no mesmo segmento de atividade econômica (classificação CNAE-3). 


\section{Apresentação dos resultados}

As informações do banco de dados criado pelo IPEA foram utilizadas para estimar equações de produtividade do trabalho através dos métodos de efeitos aleatórios (EA).

Todas as regressōes reproduzidas nas Tabelas 2 a 5 foram realizadas considerando todas as firmas das respectivas amostras, independentemente de apresentarem ou não dados para todos os anos. Analisamos, portanto, apenas os painéis não equilibrados (unbalanced), ou seja, sem restringir a amostra. Em todas as regressões, foram incluídas variáveis dummy para setor, região e ano.

Primeiramente, em todos os modelos, a variável dependente é a produtividade das empresas e a interpretação dos coeficientes das variáveis explicativas nos dá as respectivas elasticidades. Vale esclarecer que, no método de EA, a adequação do conjunto de variáveis utilizado na especificação do modelo é testada através da estatística Wald, que se mostrou significativa.

De acordo com o Modelo 1A, em particular, analisamos o efeito de transbordamento direto da presença de IED (ver Tabela 2), através da dummy ETN, que indica a origem do capital da firma. O seu coeficiente de sinal positivo revelou que, de fato, as firmas estrangeiras têm, em média, produtividade do trabalho mais elevada do que as firmas de capital majoritariamente nacional. Todos os outros coeficientes, que representam elasticidades, mostraram os sinais esperados.

Em seguida, na tentativa de comparar os efeitos específicos de cada setor selecionado, foi incluída no Modelo 1B a variável que mede o transbordamento intersetorial para trás, o qual foi estimado para cinco amostras extraídas de cadeias diferentes, em que permaneceram apenas as firmas domésticas.

$\mathrm{Na}$ Tabela 3, portanto, as elasticidades dos efeitos de transbordamento para trás foram heterogêneas entre as cinco cadeias produtivas e, na maioria, foram não significativas. A exceção foi o setor de farmacêuticos, que apresentou elasticidade positiva e significativa, indicando que a variação de $1 \%$ na presença estrangeira no setor farmacêutico está associada à variação média de $0,48 \%$ da produtividade de seus fornecedores domésticos.

Em geral, os resultados são no sentido de efeitos positivos e significativos do tamanho da firma - medido pelo pessoal ocupado -, da qualificação da mão de obra empregada e dos coeficientes de importação e de exportação sobre a produtividade do trabalho ao nível da firma. O tamanho, entre os fatores explicativos da produtividade das firmas domésticas, foi o de maior importância. 
Marina Filgueiras Jorge, Alexis Toribio Dantas

TABELA 2

Transbordamento direto de produtividade a partir da presença de capital estrangeiro nas empresas, no período 1998-2003

Painel não balanceado - Todas as empresas

\begin{tabular}{|c|c|}
\hline Variável dependente: in(produtividade) & Efeitos aleatórios \\
\hline Pessoal ocupado & $\begin{array}{c}0,15998 * * * \\
(0,00958)\end{array}$ \\
\hline Percentual de pessoas com nível superior & $\begin{array}{c}0,03198 * * * \\
(0,00159)\end{array}$ \\
\hline ETN & $\begin{array}{c}0,59228 * * * \\
(0,03226)\end{array}$ \\
\hline Coeficiente de importação & $\begin{array}{c}0,03956 * * * \\
(0,00153)\end{array}$ \\
\hline Coeficiente de exportação & $\begin{array}{c}0,02809 * * * \\
(0,00155)\end{array}$ \\
\hline dummy 1999 & $\begin{array}{c}-0,08345^{* * *} \\
(0,01343)\end{array}$ \\
\hline dummy 2000 & (base) \\
\hline dummy 2001 & $\begin{array}{c}0,07014 * * * \\
(0,01305)\end{array}$ \\
\hline dummy 2002 & $\begin{array}{c}0,16767 * * * \\
(0,01313)\end{array}$ \\
\hline dummy 2003 & $\begin{array}{c}0,29300 * * * \\
(0,01323)\end{array}$ \\
\hline $\mathrm{R}^{2}$ & 0.2308 \\
\hline Número de observações & 74.500 \\
\hline Estatística & Wald $=9.107$ \\
\hline
\end{tabular}

Fonte: PIA/IBGE, SECEX/MDIC, CEB/BACEN e RAIS/MTE.

*, ** $e^{* * *}$ representam níveis de significância de 10\%,5\% e 1\% respectivamente.

Obs.: As dummies de setor e região e o intercepto foram incluídos no modelo, embora omitidos na apresentação. Com exceção da variável ETN, todas as variáveis explicativas foram defasadas de um ano e expressas em logaritmo natural. 
TABELA 3

Transbordamento de produtividade em cinco cadeias produtivas diferentes, considerando apenas empresas domésticas, no período 1998-2003

\begin{tabular}{|c|c|c|c|c|c|}
\hline & \multicolumn{5}{|c|}{ Efeitos aleatórios } \\
\hline in(produtividade) & Elétrico & Eletrônico & Automóveis & Farmacêutico & Óleos vegetais \\
\hline Pessoal ocupado & $\begin{array}{c}0,17885^{* * *} \\
(0,01337)\end{array}$ & $\begin{array}{c}0,19113^{* * *} \\
(0,01447)\end{array}$ & $\begin{array}{c}0,13035^{* * *} \\
(0,01613)\end{array}$ & $\begin{array}{c}0,15026^{* * *} \\
(0,01897)\end{array}$ & $\begin{array}{c}0,12607 * * * \\
(0,01541)\end{array}$ \\
\hline $\begin{array}{l}\text { Percentual de pessoas } \\
\text { com nível superior }\end{array}$ & $\begin{array}{c}0,03583 * * * \\
(0,00196)\end{array}$ & $\begin{array}{c}0,02320 * * * \\
(0,00184)\end{array}$ & $\begin{array}{c}0,03070 * * * \\
(0,00233)\end{array}$ & $\begin{array}{c}0,04621 * * * \\
(0,00282)\end{array}$ & $\begin{array}{c}0,03418^{* * *} \\
(0,00244)\end{array}$ \\
\hline $\begin{array}{l}\text { Coeficiente de } \\
\text { importação }\end{array}$ & $\begin{array}{c}0,03922^{* * *} \\
(0,00186)\end{array}$ & $\begin{array}{c}0,03003^{* * *} \\
(0,00201)\end{array}$ & $\begin{array}{c}0,03376^{* * *} \\
(0,00217)\end{array}$ & $\begin{array}{c}0,04482^{* * *} \\
(0,00267)\end{array}$ & $\begin{array}{c}0,03957 * * * \\
(0,00215)\end{array}$ \\
\hline $\begin{array}{l}\text { Coeficiente de } \\
\text { exportação }\end{array}$ & $\begin{array}{l}0,02333 * * * \\
(0,00205)\end{array}$ & $\begin{array}{c}0,03229 * * * \\
(0,00188)\end{array}$ & $\begin{array}{c}0,02072 * * * \\
(0,00225)\end{array}$ & $\begin{array}{c}0,02560 * * * \\
(0,00315)\end{array}$ & $\begin{array}{c}0,02420 * * * \\
(0,00243)\end{array}$ \\
\hline $\begin{array}{l}\text { Transbordamento } \\
\text { intersetorial para trás }\end{array}$ & $\begin{array}{c}0,03355 n . s . \\
(0,08315)\end{array}$ & $\begin{array}{c}-0,04237 n . s . \\
(0,09533)\end{array}$ & $\begin{array}{c}-0,04250 n . s . \\
(0,04275)\end{array}$ & $\begin{array}{l}0,47785^{* *} \\
(0,25078)\end{array}$ & $\begin{array}{c}-0,02447 \text { n.s. } \\
(0,0549)\end{array}$ \\
\hline $\mathrm{R}^{2}$ & 0,2208 & 0,1907 & 0,1661 & 0,2262 & 0,1428 \\
\hline Número de observações & 34.499 & 35.393 & 23.721 & 20.458 & 32.397 \\
\hline Número de grupos & 10.529 & 11.076 & 7.356 & 6.110 & 10.012 \\
\hline Estatística Wald & 3.906 & 3.388 & 1.998 & 2.398 & 610.647 \\
\hline
\end{tabular}

Fonte: PIA/IBGE, SECEX/MDIC, CEB/BACEN e RAIS/MTE.

*, ** $e^{* * *}$ representam níveis de significância de 10\%,5\% e 1\% respectivamente; e n.s., não significativo a $10 \%$. Obs.: As dummies de ano, setor e região e o intercepto foram incluídos no modelo, embora omitidos na apresentação. Todas as variáveis explicativas foram defasadas de um ano e expressas em logaritmo natural. 
Nas Tabelas 4 e 5, usando os modelos do segundo grupo que foram especificados anteriormente, controlamos a capacidade de absorção das firmas domésticas, ao interagir o efeito de transbordamento indireto com os esforços tecnológicos e o perfil da mão de obra respectivamente.

Na Tabela 4, a capacidade de absorção foi representada nos moldes do Modelo 2A, ao interagir o efeito de transbordamento indireto e os gastos em $\mathrm{P} \& \mathrm{D}$ realizados pela empresa. $\mathrm{O}$ transbordamento intersetorial para trás é não significativo a $10 \%$ em praticamente todos os resultados, sendo positivo e significativo a $10 \%$ apenas para a cadeia de farmacêuticos e de eletrônicos.

O que mais chama atenção no resultado da estimação desse modelo é o impacto negativo da capacidade de absorção da empresa doméstica sobre a sua produtividade, embora não significativo, em praticamente todas as amostras. De fato, à exceção dos resultados para as elasticidades da produtividade das firmas domésticas das cadeias referentes aos setores eletrônico e farmacêutico com respeito à sua capacidade de absorção, os demais resultados obtidos com todos os três métodos de estimação usados nas cadeias de produção de elétricos, automóveis e óleos vegetais, são no sentido de que, ao contrário, a existência de capacidade de absorção de tecnologia é um fator negativo para o aumento da produtividade do fornecedor local de insumos.

Para a estimação da equação do Modelo $2 \mathrm{~B}$, as variáveis $\ln \left(E P_{-} P O_{i j, t-1}\right)$ e $\ln \left(C A_{-} P O_{j, t-1}\right)$ apresentaram correlação muito alta, causando problemas de multicolinearidade. A equação estimada, portanto, excluiu a variável $\ln \left(E P_{-} P O_{i j, t-1}\right)$, que representava a eficiência produtiva da firma medida pela proporção de pessoal ocupado com nível de instrução superior.

$\mathrm{Na}$ Tabela 5, o transbordamento intersetorial para trás é positivo na cadeia dos produtos farmacêuticos e negativo na de automóveis ao nível de significância de $10 \%$. Nas outras três, o efeito é negativo e não significativo a $10 \%$.

Como resultado do uso da qualificação da mão de obra como proxy para a capacidade de absorção, as estimativas apontam efeito positivo e significativo em todas as cadeias produtivas, ou seja, os resultados sugerem que quanto mais trabalhadores altamente qualificados dentro do quadro de pessoal das firmas, maiores as chances de elas absorverem o conhecimento tecnológico externo e se beneficiarem de transbordamentos de produtividade a partir da presença das firmas estrangeiras, e a capacidade de absorção teve maior impacto sobre a produtividade nas empresas localizadas na cadeia de produtos farmacêuticos. 
Investimento Estrangeiro Direto, Transbordamento e Produtividade

TABELA 4

Transbordamento de produtividade em cinco cadeias produtivas diferentes, considerando a capacidade de absorção das empresas domésticas, no período 1998-2003

\begin{tabular}{|c|c|c|c|c|c|}
\hline \multirow{2}{*}{ Variável dependente: } & \multicolumn{5}{|c|}{ Efeitos aleatórios } \\
\hline & Elétrico & Eletrônico & Automóveis & Farmacêutico & Óleos vegetais \\
\hline Pessoal ocupado & $\begin{array}{c}0,17886^{* * *} \\
(0,01350)\end{array}$ & $\begin{array}{c}0,19893^{* * *} \\
(0,01459)\end{array}$ & $\begin{array}{c}0,13131 * * * \\
(0,01641)\end{array}$ & $\begin{array}{c}0,15107 * * * \\
(0,01916)\end{array}$ & $\begin{array}{c}0,12668^{* * *} \\
(0,01565)\end{array}$ \\
\hline $\begin{array}{l}\text { Percentual de pessoas } \\
\text { com nível superior }\end{array}$ & $\begin{array}{c}0,03583^{* * *} \\
(0,00196)\end{array}$ & $\begin{array}{c}0,02327^{* * *} \\
(0,00184)\end{array}$ & $\begin{array}{c}0,03070^{* * *} \\
(0,00233)\end{array}$ & $\begin{array}{c}0,04619^{* * *} \\
(0,00282)\end{array}$ & $\begin{array}{c}0,03419^{* * *} \\
(0,00244)\end{array}$ \\
\hline $\begin{array}{l}\text { Coeficiente de } \\
\text { importação }\end{array}$ & $\begin{array}{c}0,03922 * * * \\
(0,00186)\end{array}$ & $\begin{array}{c}0,03007 * * * \\
(0,00201)\end{array}$ & $\begin{array}{c}0,03377^{* * *} \\
(0,00217)\end{array}$ & $\begin{array}{c}0,04482 * * * \\
(0,00267)\end{array}$ & $\begin{array}{c}0,03959 * * * \\
(0,00215)\end{array}$ \\
\hline $\begin{array}{l}\text { Coeficiente de } \\
\text { exportação }\end{array}$ & $\begin{array}{c}0,02333^{* * *} \\
(0,00205)\end{array}$ & $\begin{array}{c}0,03233^{* * *} \\
(0,00188)\end{array}$ & $\begin{array}{c}0,02074^{* * *} \\
(0,00225)\end{array}$ & $\begin{array}{c}0,02563^{* * *} \\
(0,00316)\end{array}$ & $\begin{array}{c}0,02420^{* * *} \\
(0,00243)\end{array}$ \\
\hline $\begin{array}{l}\text { Transbordamento } \\
\text { intersetorial para trás }\end{array}$ & $\begin{array}{c}\text { 0,03357n.s. } \\
(0,08330)\end{array}$ & $\begin{array}{c}-0,03098 \text { n.s. } \\
(0,09538)\end{array}$ & $\begin{array}{c}-0,04280 \text { n.s. } \\
(0,04277)\end{array}$ & $\begin{array}{l}0,47592^{*} \\
(0,25087)\end{array}$ & $\begin{array}{c}-0,02429 \text { n.s. } \\
(0,05498)\end{array}$ \\
\hline $\begin{array}{l}\text { Capacidade de absorção* } \\
\text { Transbordamento } \\
\text { (investimentos em P\&D) }\end{array}$ & $\begin{array}{c}-0,00008 \text { n.s. } \\
(0,00171)\end{array}$ & $\begin{array}{c}-0,00728 * * * \\
(0,00188)\end{array}$ & $\begin{array}{c}-0,00086 \text { n.s. } \\
(0,00273)\end{array}$ & $\begin{array}{c}-0,00062^{* * *} \\
(0,00204)\end{array}$ & $\begin{array}{c}-0,00051 \text { n.s. } \\
(0,00229)\end{array}$ \\
\hline $\mathrm{R}^{2}$ & 0,2208 & 0,1919 & 0,1661 & 0,2262 & 0,1428 \\
\hline Número de observações & 34.499 & 35.393 & 23.721 & 20.458 & 32.397 \\
\hline
\end{tabular}

Fonte: PIA/IBGE, SECEX/MDIC, CEB/BACEN e RAIS/MTE.

*,${ }^{* *} e^{* * *}$ representam níveis de significância de 10\%,5\% e 1\% respectivamente; e n.s., não significativo a $10 \%$. Obs.: As dummies de ano, setor e região e o intercepto foram incluídos no modelo, embora omitidos na apresentação. Todas as variáveis explicativas foram defasadas de um ano e expressas em logaritmo natural. 
Marina Filgueiras Jorge, Alexis Toribio Dantas

TABELA 5

Transbordamento de produtividade em cinco cadeias produtivas diferentes, considerando a capacidade de absorção das empresas domésticas, no período 1998-2003

\begin{tabular}{|c|c|c|c|c|c|}
\hline \multirow{2}{*}{$\begin{array}{l}\text { Variável dependente: } \\
\text { in(produtividade) }\end{array}$} & \multicolumn{5}{|c|}{ Efeitos aleatórios } \\
\hline & Elétrico & Eletrônico & Automóveis & Farmacêutico & Óleos vegetais \\
\hline Pessoal ocupado & $\begin{array}{c}0,17885^{* * *} \\
(0,01337)\end{array}$ & $\begin{array}{c}0,19099 * * * \\
0,01442)\end{array}$ & $\begin{array}{c}0,13225^{* * *} \\
(0,01614)\end{array}$ & $\begin{array}{c}0,14785^{* * *} \\
(0,01890)\end{array}$ & $\begin{array}{c}0,12571^{* * *} \\
(0,01543)\end{array}$ \\
\hline $\begin{array}{l}\text { Coeficiente de } \\
\text { importação }\end{array}$ & $\begin{array}{c}0,03911^{* * *} \\
(0,00187)\end{array}$ & $\begin{array}{c}0,03000 * * * \\
0,00201)\end{array}$ & $\begin{array}{c}0,03351 * * * \\
(0,00217)\end{array}$ & $\begin{array}{c}0,04510^{* * *} \\
(0,00267)\end{array}$ & $\begin{array}{c}0,03945^{* * *} \\
(0,00216)\end{array}$ \\
\hline $\begin{array}{l}\text { Coeficiente de } \\
\text { exportação }\end{array}$ & $\begin{array}{c}0,02365^{* * *} \\
(0,00206)\end{array}$ & $\begin{array}{c}0,03270^{* * *} \\
0,00188)\end{array}$ & $\begin{array}{c}0,02106^{* * *} \\
(0,00226)\end{array}$ & $\begin{array}{c}0,02553^{* * *} \\
(0,00315)\end{array}$ & $\begin{array}{c}0,02434^{* * *} \\
(0,00244)\end{array}$ \\
\hline $\begin{array}{l}\text { Transbordamento } \\
\text { intersetorial para trás }\end{array}$ & $\begin{array}{c}-0,00641 \text { n.s. } \\
(0,08324)\end{array}$ & $\begin{array}{c}-0,06053 \text { n.s. } \\
(0,09524)\end{array}$ & $\begin{array}{l}-0,07451^{*} \\
(0,04284)\end{array}$ & $\begin{array}{l}0,43503^{*} \\
(0,24987)\end{array}$ & $\begin{array}{c}-0,06036 \text { n.s. } \\
(0,05511)\end{array}$ \\
\hline $\begin{array}{l}\text { Capacidade de absorção* } \\
\text { Transbordamento } \\
\text { (\% pessoal ocupado } \\
\text { com nível superior) }\end{array}$ & $\begin{array}{c}0,03608^{* * *} \\
(0,00196)\end{array}$ & $\begin{array}{c}0,02354^{* * *} \\
(0,00184)\end{array}$ & $\begin{array}{c}0,03104 * * * \\
(0,00233)\end{array}$ & $\begin{array}{c}0,04656^{* * *} \\
(0,00282)\end{array}$ & $\begin{array}{c}0,03446 * * * \\
(0,00245)\end{array}$ \\
\hline$R^{2}$ & 0,2214 & 0,1921 & 0,1667 & 0,2286 & 0,1429 \\
\hline Número de observações & 34.255 & 35.147 & 23.543 & 20.319 & 32.183 \\
\hline Número de grupos & 10.473 & 11.007 & 7.322 & 6.070 & 9.966 \\
\hline Estatística Wald & 3.924 & 3.436 & 608.558 & 2.437 & 2.397 \\
\hline
\end{tabular}

Fonte: PIA/IBGE, SECEX/MDIC, CEB/BACEN e RAIS/MTE.

*, ** $e^{* * *}$ representam níveis de significância de $10 \%, 5 \%$ e 1\% respectivamente; e n.s., não significativo a $10 \%$. Obs.: As dummies de ano, setor e região e o intercepto foram incluídos no modelo, embora omitidos na apresentação. Todas as variáveis explicativas foram defasadas de um ano e expressas em logaritmo natural.

506 RBI, Rio de Janeiro (RJ), 8 (2), p.481-514, julho/dezembro 2009 


\section{Análise dos resultados}

Em primeiro lugar, uma vez que as variáveis relacionadas à estrutura produtiva de uma empresa não apresentam grande variação em um período curto de tempo, como o analisado, o método de EA passa a ser a melhor alternativa para conseguir tirar conclusões sobre as variáveis de interesse. Vale dizer que, supostamente, em um estudo baseado em uma série histórica mais longa, em que as variáveis econômicas apresentem maior variação, essa hipótese subjacente tenha maior utilidade. Assim como em um estudo que inclua mais variáveis que representem qualidades específicas das firmas, de modo que os efeitos individuais não tenham tanto poder de explicação (Filgueiras Jorge, 2007).

Em segundo lugar, podemos verificar que, em geral, os valores do $\mathrm{R}^{2}$ não foram altos nos modelos estimados. $\mathrm{O} \mathrm{R}^{2}$ baixo sugere que a variância dos fatores omitidos é alta em relação à variância da variável dependente, podendo gerar estimadores com pouca precisão. No estudo realizado, no entanto, esse problema pode ter sido compensado pelo tamanho da amostra. O número suficiente de informações em cortes transversais pode dar condições para estimar com precisão os efeitos parciais das variáveis explicativas apresentadas (Wooldridge, 2006). O R ${ }^{2}$ baixo significa, apenas, que inúmeros fatores que afetam a produtividade do trabalho não foram avaliados e talvez pudessem ser incluídos em outro exercício.

O modelo estimado, em resumo, buscou verificar se o IED, justamente nos setores em que a presença estrangeira é mais intensa, teria potencial para gerar transformação estrutural na indústria, no sentido de promover ganhos de competitividade não efêmeros nas cadeias industriais relativas a produtos de maior valor agregado. Pelo menos no período analisado (1998-2003), no entanto, não há evidências, entre os resultados, de que o transbordamento do IED para a empresa fornecedora de insumos doméstica tenha gerado uma mudança estrutural dessa natureza.

Os resultados apresentados, no entanto, indicam, primeiro, que os efeitos indiretos da presença do IED não são tão significativos quanto os efeitos diretos; segundo, não sinalizam a existência de transformação estrutural por conta da penetração do capital estrangeiro; e, terceiro, mostram que há diferenças relevantes entre os setores.

Além disso, esperávamos que o maior investimento em $\mathrm{P} \& \mathrm{D}$ das empresas domésticas, no transbordamento indireto das empresas estrangeiras, afetasse positivamente a produtividade das primeiras, uma vez que a realização de pesquisas em desenvolvimento de produtos e processos pode facilitar o aprendizado do 
conhecimento tecnológico mais avançado. Nesse sentido, as empresas com maior investimento em P\&D deveriam ser as principais beneficiadas por uma eventual transferência de conhecimento de ETNs para empresas domésticas. Os resultados, no entanto, mostraram o contrário.

Ao contrário dos resultados inesperados e inconclusivos a respeito da capacidade de absorção medida pelo investimento em $\mathrm{P} \& \mathrm{D}$, porém, a maior qualificação da mão de obra mostrou ser um importante elemento para o aproveitamento do transbordamento tecnológico. Assim, ampliar a base de trabalhadores qualificados nas empresas industriais possibilita o maior aprendizado de conhecimentos externos, disponíveis nas empresas estrangeiras, mesmo no curto horizonte de tempo coberto pela análise.

Visto que os resultados de transbordamentos intersetoriais apresentaram diferenças relevantes entre os setores, as conclusōes são no sentido, portanto, da não efetividade das políticas horizontais de atração de IED. Não faz sentido assumir a atração de IED como uma politica unificada, formulada exclusivamente com instrumentos de uso geral, dado que seus impactos não são garantidos. Para otimizar o uso dos recursos destinados a subsidios e otimizar os resultados dos transbordamentos, deve haver um grau de seletividade. Como mostram os resultados, instrumentos verticais que aproveitam as potencialidades setoriais podem ser mais eficientes na promoção da competitividade.

Os instrumentos utilizados neste trabalho, embora necessários para verificar a heterogeneidade setorial, não foram construídos para substituir maiores explicações individualizadas e sim orientar a sua investigação, ou seja, o objetivo desta pesquisa não se estendeu à análise setorial mais minuciosa, mas o estado atual de conhecimento sobre os transbordamentos justificam prosseguir com estudos setoriais e com estudos de caso de empresas em paralelo.

\section{Considerações finais}

O novo processo de globalização que transformou o cenário mundial foi marcado pelo aumento do investimento estrangeiro direto e do comércio entre países. Ao mesmo tempo, o conhecimento tem representado um fator determinante de competitividade das economias e a maior integração entre elas tem contado, ainda, com o aumento significativo da presença das ETNs nos fluxos de IED e de comércio exterior.

No cenário internacional, os países que mais cresceram nos últimos anos apresentaram forte participação da indústria no PIB, e o maior dinamismo das suas exportaçóes esteve associado aos produtos manufaturados, principalmente daqueles 
de maior intensidade tecnológica. Nos países em desenvolvimento de maior dinamismo, principalmente, a indústria tem sido o motor do crescimento da economia.

No Brasil, inicialmente, acreditou-se que a abertura econômica pudesse garantir ganhos de competitividade para a indústria e a sua melhor inserção no comércio internacional. Verificou-se, entretanto, que, apesar de ganhos de competitividade, a participação do produto industrial brasileiro se manteve estagnada, evidenciando seu baixo dinamismo. E, quanto à inserção brasileira no comércio internacional, a estrutura da pauta de exportaçôes manteve-se praticamente inalterada e concentrada nos grupos de menor dinamismo, principalmente no das commodities primárias.

A maior integração produtiva contou, também, com o aumento dos fluxos de capital entre as economias. As ETNs, por possuírem inúmeras subsidiárias e em diferentes localidades, podem aproveitar melhor as dotaçōes de fatores, como acesso a insumos mais baratos, mercados de conhecimento, técnicas de contabilidade centralizada, experiência administrativa e P\&D. Além disso, elas apresentam algumas vantagens competitivas, como o fato de serem mais produtivas e naturalmente mais integradas ao comércio internacional através das relaçōes com outras parceiras de sua corporação.

No Brasil, a maior participação dessas empresas na produção industrial e no comércio foi vista, inicialmente, como uma possibilidade para a transferência de conhecimentos específicos para as empresas domésticas. Seguindo a tendência da maioria dos países em desenvolvimento, a atração de IED foi adotada como uma política tecnológica. Acreditava-se que a presença das ETNs poderia contribuir para a capacidade tecnológica doméstica, através dos efeitos indiretos associados à transferência de seus conhecimentos mais avançados.

Os encadeamentos produtivos tenderiam a ser os canais mais favoráveis à transferência desses conhecimentos para os seus fornecedores domésticos, uma vez que esses elos não representariam relaçôes concorrenciais. As ETNs poderiam conduzir ao aumento da produção e do nível de emprego dos fornecedores domésticos e, ainda, realizar papel de difusoras de conhecimento e capacidades, uma vez que os elos produtivos criados entre empresas permitem a troca de informação, de conhecimento técnico e de capacitação.

A análise realizada neste trabalho, no entanto, sugere que os efeitos microeconômicos da maior presença do capital estrangeiro na economia brasileira foram heterogêneos. As evidências indicaram a existência de vantagens competitivas, em termos de produtividade, das ETNs aqui instaladas, em relação às empresas domésticas. Esse diferencial de desempenho, no entanto, não se mostrou uma fonte 
de transferência de conhecimentos tecnológicos que pudesse refletir em ganhos de produtividade para as empresas fornecedoras domésticas.

Algumas considerações do comportamento dessas empresas são importantes. Por mais que as empresas estrangeiras ainda tenham apresentado maior elo com suas matrizes, elas ainda parecem interagir mais com o Sistema Nacional de Inovação e Aprendizagem brasileiro, do que as próprias empresas brasileiras. Portanto, é necessário estimular as empresas nacionais a desenvolverem sua capacitação tecnológica e melhor interagirem com o ambiente institucional.

De fato, o que se viu foi que a capacidade de aprendizado e de absorção de conhecimentos externos depende do desenvolvimento tecnológico prévio da estrutura da firma. A absorção do conhecimento tecnológico incorporado nos fluxos externos de capitais e nos fluxos de mercadorias é consequência do desenvolvimento interno.

No Brasil, em particular, os investimentos em atividades de inovação ainda são vistos com cautela pelo empresariado e os ganhos de competitividade estiveram associados à escolha por modernização. $\mathrm{O}$ investimento em $\mathrm{P} \& \mathrm{D}$, ainda que pouco difundido entre as empresas brasileiras, foi um fator determinante para explicar o maior crescimento das empresas brasileiras.

No modelo estimado, no entanto, o investimento em $P \& D$ não se mostrou um fator significativo para a capacidade de absorção do conhecimento das empresas estrangeiras. Como sugestôes para pesquisas futuras, essa variável deve ser mais bem especificada, além de quantificada a partir de informaçóes menos agregadas do que a que utilizamos aqui e para um período de tempo mais longo, pois é um consenso na literatura e em trabalhos empíricos que o esforço inovador da firma é um importante fator para explicar a sua capacidade de absorção e a sua competitividade.

Por outro lado, a intensidade da qualificação da mão de obra, ao interagir com a presença estrangeira, permitiu à empresa doméstica extrair transbordamento positivo de produtividade, mostrando que, quanto mais trabalhadores altamente qualificados dentro do quadro de pessoal da firma, maiores as chances de essa empresa absorver o conhecimento tecnológico externo e se beneficiar de transbordamentos de produtividade.

O modelo estimado neste trabalho, em suma, trouxe informações relevantes sobre o problema formulado, que é sobre a possibilidade do transbordamento do IED gerar transformaçôes estruturais na indústria brasileira.

Como havia sido apontado por alguns autores, o transbordamento de produtividade não é resultado automático da presença de empresas estrangeiras. A política de atração de IED não pode ser considerada suficiente como política tecnológica, 
pois os processos de absorção de tecnologia e de mudanças estruturais não se configuram em ambientes passivos de aprendizado.

O modelo permite, além disso, identificar os setores candidatos à assistência de políticas ativas, ou seja, de políticas de promoção da competitividade. As especificidades setoriais, portanto, devem ser levadas em consideração para o desenvolvimento e o fortalecimento dos elos produtivos e do papel da firma como canal e agente ativos de aprendizado e de esforço inovador.

E, finalmente, como última sugestāo para pesquisas futuras, uma modelagem voltada a captar efeitos dinâmicos do transbordamento é necessária, considerando que existe um tempo de desenvolvimento para que as firmas se beneficiem do transbordamento da presença da empresa estrangeira. Essa sugestão se baseia na suposição de que o efeito indireto de transbordamento de conhecimento leva certo tempo para refletir em maior produtividade. Neste trabalho, utilizamos a defasagem de um ano, mas pode ser relevante refazer o exercício com uma série de tempo mais longa, que possibilite defasagens maiores.

\section{Referências bibliográficas}

Araújo, R.D. "Esforços tecnológicos das firmas transnacionais e domésticas", in De Negri, J.A.; Salerno, M.S. (orgs.), Inovações, padröes tecnológicos e desempenho das firmas industriais brasileiras. Brasília: IPEA, 2005.

Araújo, R.D.; Hiratuka, C. "Exportações das firmas domésticas e influência das firmas transnacionais", in De Negri, J.A.; Araújo, B. (orgs.), As empresas brasileiras e o comércio internacional. Brasília: IPEA, 2007.

BACEN. Investimento estrangeiro direto/Censos 1995/2000 e Ingressos 2001 a 2006. Banco Central do Brasil. Disponível em <http://www.bcb.gov.br/rex/IED/Port/Ingressos/ planilhas/DivugacaoAtividades95-06.xls>. Acesso em 1o de setembro de 2007.

Bielschowsky, R. (coord.) Investimento e reformas no Brasil: indístria e infra-estrutura nos anos 1990. Brasília: IPEA, CEPAL, 2002.

Bonelli, R. A note on Foreign Direct Investment (FDI) and industrial competitiveness in Brazil. Rio de Janeiro: IPEA, 1998, Texto para Discussão, n.584. 
Chudnovsky, D. et al. Foreign direct investment spillovers and the absorption capabilities of domestic firms in the Argentine manufacturing sector (1992-2001). UDESA, abr., 2004, Documento de Trabajo, n.74.

Ciarli, T.; Giuliani, E. "Inversión extranjera directa y encadenamientos productivos en Costa Rica”, in Cimoli, M. (org.), Heterogeneidad estructural, asimetrías tecnológicas y crecimiento en América Latina. Santiago de Chile: BID, CEPAL, 2005.

Cimoli, M. et al. "Cambio estructural, heterogeneidad productiva y tecnología en América Latina”, in Cimoli, M. (org.), Heterogeneidad estructural, asimetrías tecnológicas y crecimiento en América Latina. Santiago de Chile: BID, CEPAL, 2005.

De Negri, F. "Desempenho comercial das empresas estrangeiras no Brasil na década de 90", Dissertação de Mestrado, IE-UNICAMP. Campinas, 2003.

"Determinantes da capacidade de absorção das firmas brasileiras: Qual a influência do perfil da mão-de-obra?", in De Negri, J.A.; De Negri, F.; Coelho, D. (orgs.), Tecnologia, exportação e emprego. Brasília: IPEA, 2006.

Dunning, J.H. "Multinational enterprises and the globalization of innovatory capacity", Research Policy, v.23, p.67-88, 1994.

Ferraz, J.C.; Kupfer, D.; Iooty, M. "Made in Brazil: industrial competitiveness 10 years after economic liberalisation", CEPAL Review, n.82, abr., 2003.

Filgueiras Jorge, M. "Investimento estrangeiro direto e inovação: um estudo sobre ramos selecionados da indústria no Brasil", Dissertação de Mestrado, FCE-UERJ. Rio de Janeiro, 2007.

Franco, G. "A inserção externa e o desenvolvimento", Revista de Economia Política, v.18, n.3(71), p.121-147, jul-set., 1998.

Fritsch, W.; Franco, G. "O investimento direto estrangeiro em uma nova estratégia industrial”, Revista de Economia Política, v.9, n.2, p.5-25, 1989.

Gonçalves, J.E.P. "Empresas estrangeiras e transbordamentos de produtividade na indústria brasileira: 1997-2000”, Dissertação de Mestrado, IE-UNICAMP. Campinas, 2003.

Hiratuka, C. The role of transnational corporations in the Brazilian national system if innovation. NEIT, UNICAMP, abr., 2003, Texto para Discussão, v.1, n.3.

Hiratuka, C. et al. "Inserção brasileira no comércio mundial no período 1995-2005", Boletim NEIT, n.9, p.1-7, ago., 2007. Disponível em <http://www.eco.unicamp.br/neit/ boletim.htm>. Acesso em 1ำ de outubro de 2007.

IBGE. Pesquisa Industrial de Inovação Tecnológica-PINTEC 2003. Rio de Janeiro: IBGE, 2005. 
Javorcik, B.S. "Does foreign direct investment increase the productivity of domestic firms? In search of spillovers through backward linkages", American Economic Review, v.94, n.3, p.605-627, jun., 2004.

Kinoshita, Y. "R\&D and technology spillovers through FDI: innovation and absorptive capacity”, CEPR Discussion Paper, n.2.775. Londres: CEPR - Center for Economic Policy Research, maio, 2001.

Kugler, M. Spillovers from foreign direct investment: Within or between industries?, Journal of Development Economics, v.80, n.2, p.444-477, ago., 2006.

Kupfer, D. "Política industrial", Econômica, Rio de Janeiro, v.5, n.2, p.281-298, dez., 2003.

Kupfer, D.; Rocha, F. "Productividad y heterogeneidad estructural en la industria brasileña", in Cimoli, M. (org.), Heterogeneidad estructural, asimetrías tecnológicas y crecimiento en América Latina. Santiago de Chile: BID, CEPAL, 2005.

Lessa, C. "Desnacionalização acelerada na indústria brasileira”, Valor Econômico, 3/7/2007, p.A15.

Sarti, F.; Laplane, M. "O investimento direto estrangeiro e a internacionalização da economia brasileira nos anos 1990”, Economia e Sociedade, v.11, n.1(18), p.63-94, jan.-jun., 2002.

Schoors, K.; Van der Tol, B. Foreign direct investment spillovers within and between sectors: evidence from Hungrian data. Ghent University, out., 2002, Working Paper, n.157.

Viotti, E.B. "National learning systems - A new approach on technological change in late industrializing economies and evidences from the cases of Brazil and South Korea", Technological Forecasting and Social Change, v.69, p.653-680, set., 2002.

Wooldridge, J.M. Introdução à econometria: uma abordagem moderna. São Paulo: Pioneira Thomson Learning, 2006.

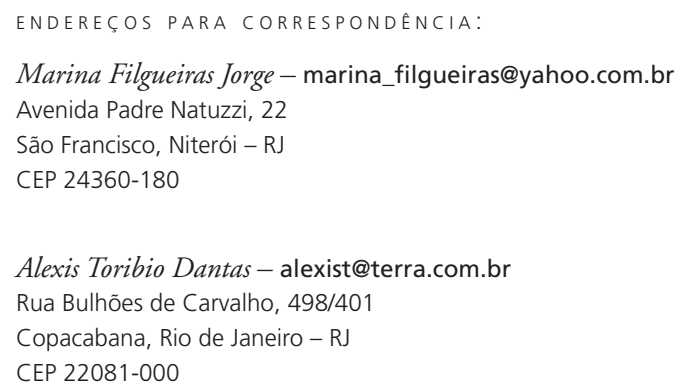




\section{ANEXO \\ Descrição das cinco cadeias produtivas selecionadas}

\section{Setor consumidor}

(10) Aparelhos elétricos

(11) Aparelhos eletrônicos

(12) Automóveis, ônibus, caminhões

(20) Produtos farmacêuticos

(30) Óleos vegetais

\section{Setores fornecedores}

04 Fabricação de minerais não metálicos

05 Siderurgia

06 Metalurgia dos não ferrosos

07 Fabricação de outros produtos metalúrgicos

08 Fabricação e manutenção de máquinas e tratores

15 Indústria de papel e gráfica

18 Refino de petróleo e indústria petroquímica

19 Fabricação de produtos químicos diversos

21 Indústria de transformação de material plástico

04 Fabricação de minerais não metálicos

06 Metalurgia dos não ferrosos

07 Fabricação de outros produtos metalúrgicos

08 Fabricação e manutenção de máquinas e tratores

10 Fabricação de aparelhos e equipamentos de material elétrico

14 Serrarias e fabricação de artigos de madeira e mobiliário

21 Indústria de transformação de material plástico

\section{Siderurgia}

07 Fabricação de outros produtos metalúrgicos

08 Fabricação e manutenção de máquinas e tratores

13 Fabricação de outros veículos, peças e acessórios

16 Indústria da borracha

19 Fabricação de produtos químicos diversos

21 Indústria de transformação de material plástico

$\longrightarrow 04$ Fabricação de minerais não metálicos
15 Indústria de papel e gráfica
17 Fabricação de elementos químicos não petroquímicos
18 Refino de petróleo e indústria petroquímica
19 Fabricação de produtos químicos diversos
21 Indústria de transformação de material plástico
30 Fabricação e refino de óleos vegetais e de gorduras para alimentação

$\longrightarrow 04$ Fabricação de minerais não metálicos

07 Fabricação de outros produtos metalúrgicos

08 Fabricação e manutenção de máquinas e tratores

14 Serrarias e fabricação de artigos de madeira e mobiliário

15 Indústria de papel e gráfica

18 Refino de petróleo e indústria petroquímica

19 Fabricação de produtos químicos diversos

21 Indústria de transformação de material plástico

22 Indústria têxtil

26 Beneficiamento de produtos de origem vegetal, inclusive fumo

27 Abate e preparação de carnes

28 Resfriamento e preparação do leite e laticínios

29 Indústria do açúcar

31 Outras indústrias alimentares e de bebidas 